\title{
Knowledge Should Be Owned by Quality Practitioners in the IT Age
}

\author{
Kuan Sheng-Pin and Perng Horng-Linn \\ CSQ/QKC, Taipei, Taiwan
}

\begin{abstract}
Industry 4.0 is a collective term including a number of automation, data exchange and manufacturing. It will create many kinds of innovative business model via customized design and marketing. From the supplier chain: purchasing, production controlling, incoming, production and shipping to the demand chain: ordering, logistics delivery, retail, and maintain service, it can integrate the all processes to be a value chain through computation, communication, controlling, collaboration and real time response. The quality requirements of all processes of the value chain would be much more transparent. As the demand chain, product and service will be required more accurate, speedy, reliable, safety, ecological, and environmental. As the supplier chain, the product and service will be required more easily to design, manufacture, change, transport, maintain, recycle and trace. Under the development of Industry 4.0, the entire value chain system will generate a large amount of data, including data related customers, data from suppliers and production, analysis of these data must apply SPC (statistical process control) and statistical techniques. Therefore, people in the value chain should strengthen the traditional quality management knowledge and skills, but also understand the development and application of ICT (information communication technology). The following are the relevant ICT knowledge and technologies of the sensing layer, the network layer, the application layer and value integration layer in the entire value chain system: (1) Sensing layer: SCADA (supervisory control and data acquisition), PLC (programmable logic controller), sensor equipments, Bar Code ID, RFID (radio frequency identification); (2) Network layer: basic network knowledge, basic knowledge of cloud computing; (3) Application layer: DBMS (database management system), MES (manufacture execution system), ERP (enterprise resource planning), PLM (product lifecycle management), CRM (customer relationship management), SCM (supplier chain management); (4) Value integration layer: hardware and software system integration engineering. This article try to summarize the ICT related knowledge should be owned by the participants of all the processes of the value chain.
\end{abstract}

Key words: Industry 4.0, supplier chain, demand chain, value chain.

\section{Introduction}

In August 1996, I first published SPC Statistical Process Control-Computerization, Automation, Real-time and Integration [1]. In the last chapter of this book "Application of SPC in Process Real-time and Automation", I mentioned the necessity of technologies such as process expertise, automatic testing, data transmission, software programs, statistical analysis, and system integration engineering, as shown in Fig. 1. Finally I proposed the real-time integrated management system architecture as a conclusion, as shown in Fig. 2.

In the year of Taiwan's education reform, higher

Corresponding author: Kuan Sheng-Pin, professor, research field: total quality management. education gradually focused on academic careers, and higher education teacher's evaluations also followed. Such kind of promotion and integration of technology are related to commercial profit, manufacturing information industry practitioners gradually added MES (manufacture execution system) with SPC (statistical process control) data collection and analysis, MES systems are commonly used in industries with high automation requirements such as semiconductors, optoelectronics, displays, EMS, etc., and academics are less concerned due to its academic values. After 20 years, when I write this article, the industry is actively implemented "Industry 4.0 " and the practitioners in the value system will become "creative creators", and from simple "Operators" are promoted to "controllers and managers". Therefore, 
quality professionals must focus on the development of related knowledge and technology in the development process of Industry 4.0.

\section{Information Knowledge Should Be Owned by Quality Practitioners}

A value chain of an industry includes supplier chain and demand chain, when the consumers on the market are willing to pay to buy the products and services which the value chain offering, then the value chain starts to add the value, who contributed more, who will get much benefit.

Industry 4.0 is a collective term including a number of automation, data exchange and manufacturing. It will create many kinds of innovative business model via customized design and marketing. From supplier chain: purchasing, production controlling, incoming, production and shipping to demand chain: ordering,

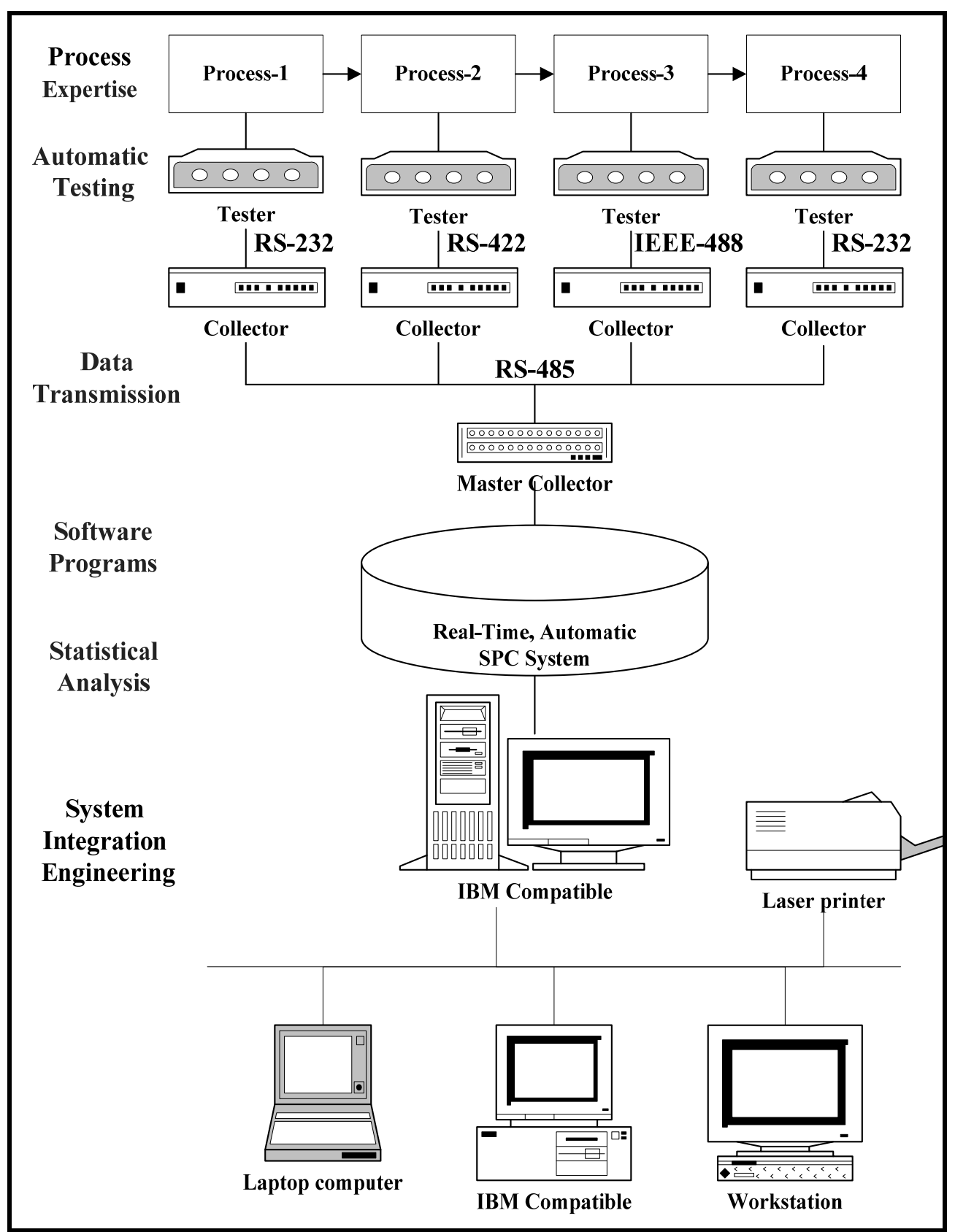

Fig. 1 Application of SPC in process real-time and automation. 


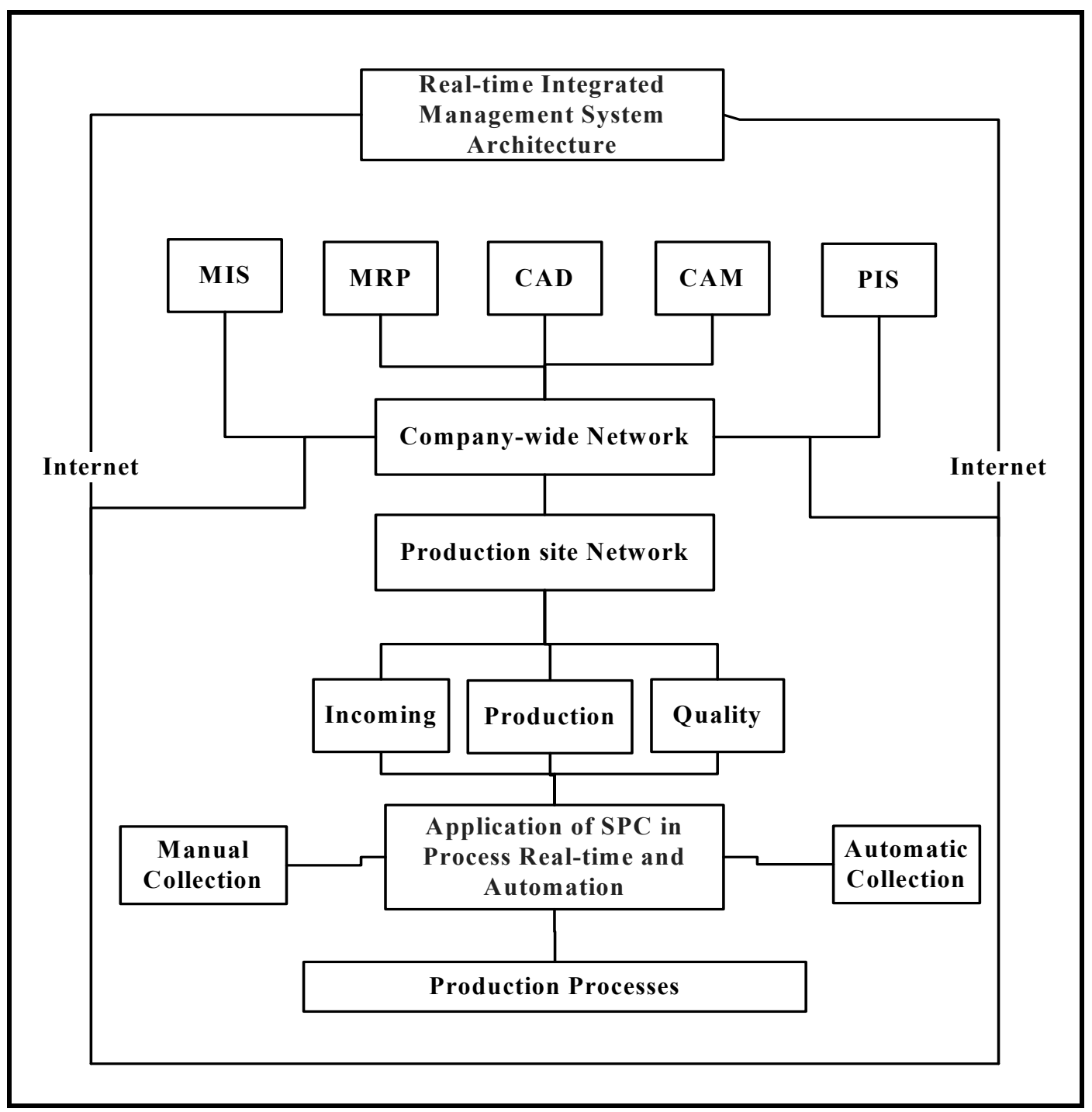

Fig. 2 Real-time integrated management system architecture.

logistics delivery, retail, and maintain service, it can integrate the all processes to be a value chain through computation, communication, controlling, collaboration and real time response, as shown in Fig. 3.

As Fig. 4: Network Services Manufacturing System, it is divided by the sensing layer, the network layer, the application layer and value integration of continuous innovation and improvement layer, and the related knowledge and technology in the different layers as shown in Table 1.

Table 1: the related knowledge and technology in the different layers, in addition to the quality related traditional knowledge, such as Metrology and
Calibration, Inspection and Test, Product Planning, Product and Process Design Methodology, Product Lifecycle Management, Reliability Design, Manufacturing Process Management, Business Process Management, TQM (total quality management), VA/VE (value analysis/value engineering), Lean Production and Continuous Improvement Mechanism, etc., the most of the rest are directly related to the development and application of ICT. Under the development of Industry 4.0 , the entire value chain system will generate a large amount of data, including data related customers, data from suppliers and production data, analysis of these data must use SPC and statistical 


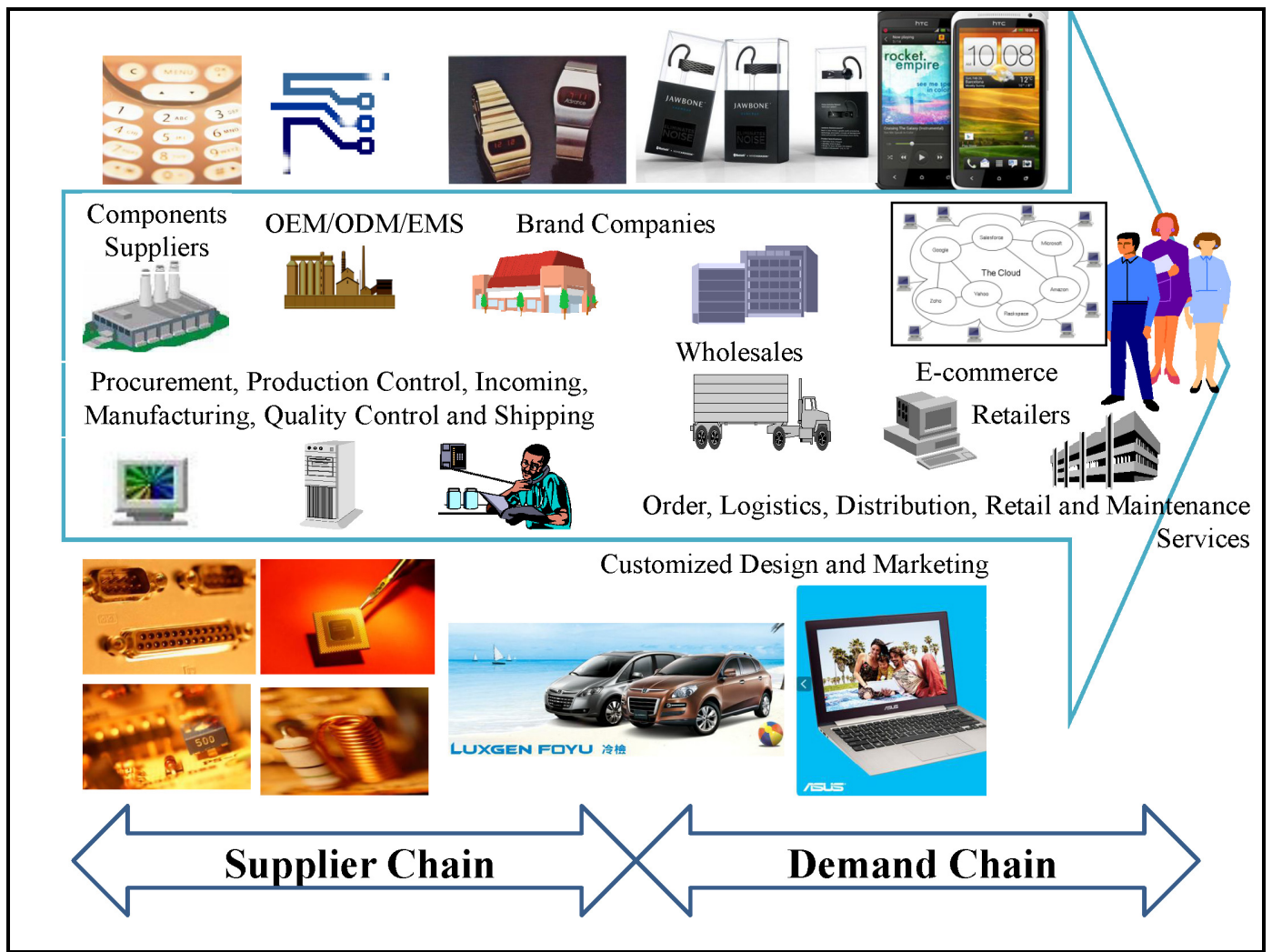

Fig. 3 Supplier chain and demand chain.

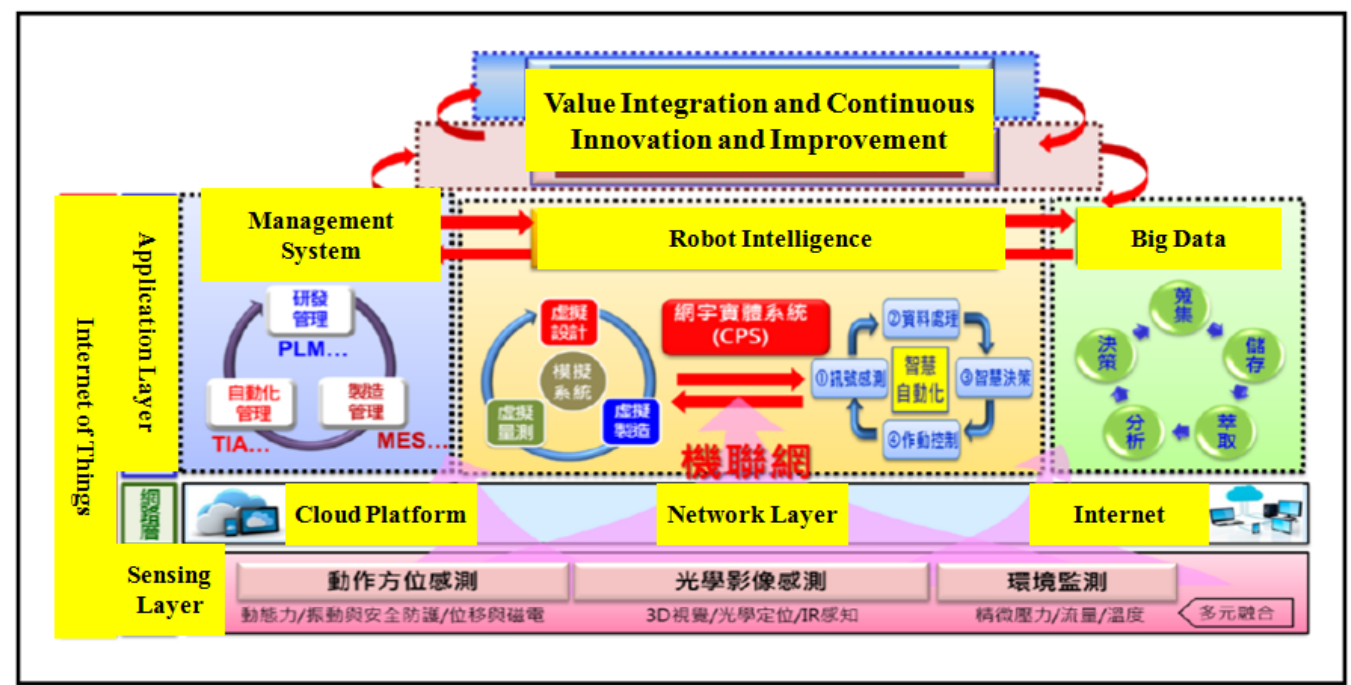

Remark: 1. JIT(Just In Time) ; SCM(Supply Chain Management )

2.PLM(Product Lifecycle Management) ; MES(Manufacturing Execution System) ; TIA(Totally Integrated Automation)

Source: Industrial Bureau of the Ministry of Economic Affairs

Fig. 4 Network services manufacturing system. 
Table 1 The related knowledge and technology in the different layers.

\begin{tabular}{ll}
\hline Layer & Related knowledge and technology \\
\hline (1) Sensing layer & $\begin{array}{l}\text { Metrology and calibration, inspection and test, automatic inspect, sensor device } \\
\text { (2) Network layer }\end{array}$ \\
$\begin{array}{l}\text { Network knowledge and technology, cloud computing knowledge and technology } \\
\text { Product planning, product and process design methodology, PLM (product lifecycle management), } \\
\text { reliability design, manufacturing process management, business process management, promodel, TPS } \\
\text { (Toyota production system), MES, automation, system integration, process control, intelligent automation, } \\
\text { TPM (total production maintenance), maintainability, ERP (enterprise resource planning), SCM (supplier } \\
\text { chain management), and big data. }\end{array}$ \\
$\begin{array}{l}\text { (3) Application layer (customer relationship management), SCM (supplier chain management), VA/VE, lean production } \\
\text { and continuous improvement mechanism. }\end{array}$ \\
\hline
\end{tabular}

techniques. Therefore, people in the value chain should strengthen the traditional quality management knowledge and skills, but also understand the development and application of ICT. The following are the relevant ICT knowledge and technologies of the sensing layer, the network layer, the application layer and value integration layer.

(1) Sensing layer: SCADA, PLC, sensor equipments, Bar Code ID, RFID;

(2) Network layer: Basic network knowledge, basic knowledge of cloud computing;

(3) Application layer: DBMS, MES, ERP, PLM, CRM, SCM;

(4) Value Integration layer: Hardware and software system integration engineering.

In the future, under the development process of Industry 4.0, it will increasingly rely on these knowledge technologies. The following is a brief description of the ICT-related knowledge and technology needed at each layer.

\section{Sensing Layer}

Some of devices and systems of sensing layer are SCADA, PLC, Sensor equipments, Bar Code ID, RFID, etc., we just illustrate one of the most important typical system, SCADA (supervisory control and data acquisition) as follows.

SCADA refers to a centralized system that can monitor and control all devices, or many systems that are dispersed in one area (as small as one plant, as large as one country). Most of the control is performed by a RTU (remote terminal control system) or PLC. The main system is generally only used for system control level, for example, in a system, the flow of cooling water in the process is controlled by the PLC, and the SCADA system allows the operator to change the target value of the flow and set warning conditions to be displayed and recorded, PLC or RTU will use feedback control to control the flow or temperature, while SCADA monitors the overall performance of the system.

Partners involved in the development of Industry 4.0 need to negotiate on multiple levels (quality, time, risk, reliability, stability, price, environmental compatibility, etc.), so the data needed in the process must be collected and monitored immediately. In order to improve the precision of dynamic negotiation, SCADA will be an important weapon.

In the production line or plant site, SCADA plays a key monitoring role. The data collected by the data collector will be transmitted to the SCADA system. According to the historical records, SCADA can record the production conditions in the normal environment, when the production environment changing, SCADA can raise related alarms. The alarm system can immediately send alarm messages to managers in a variety of ways to notify managers via SMS, Skype, and E-Mail or to monitor workstations to ensure that operators can monitor the on-site information to achieve effective monitoring purpose. Fig. 5 shows the schematic diagram of the SCADA architecture [2].

\section{Network Layer}

Some of basic network knowledge is common sense, such as Local Area Network, Wide Area Network, 


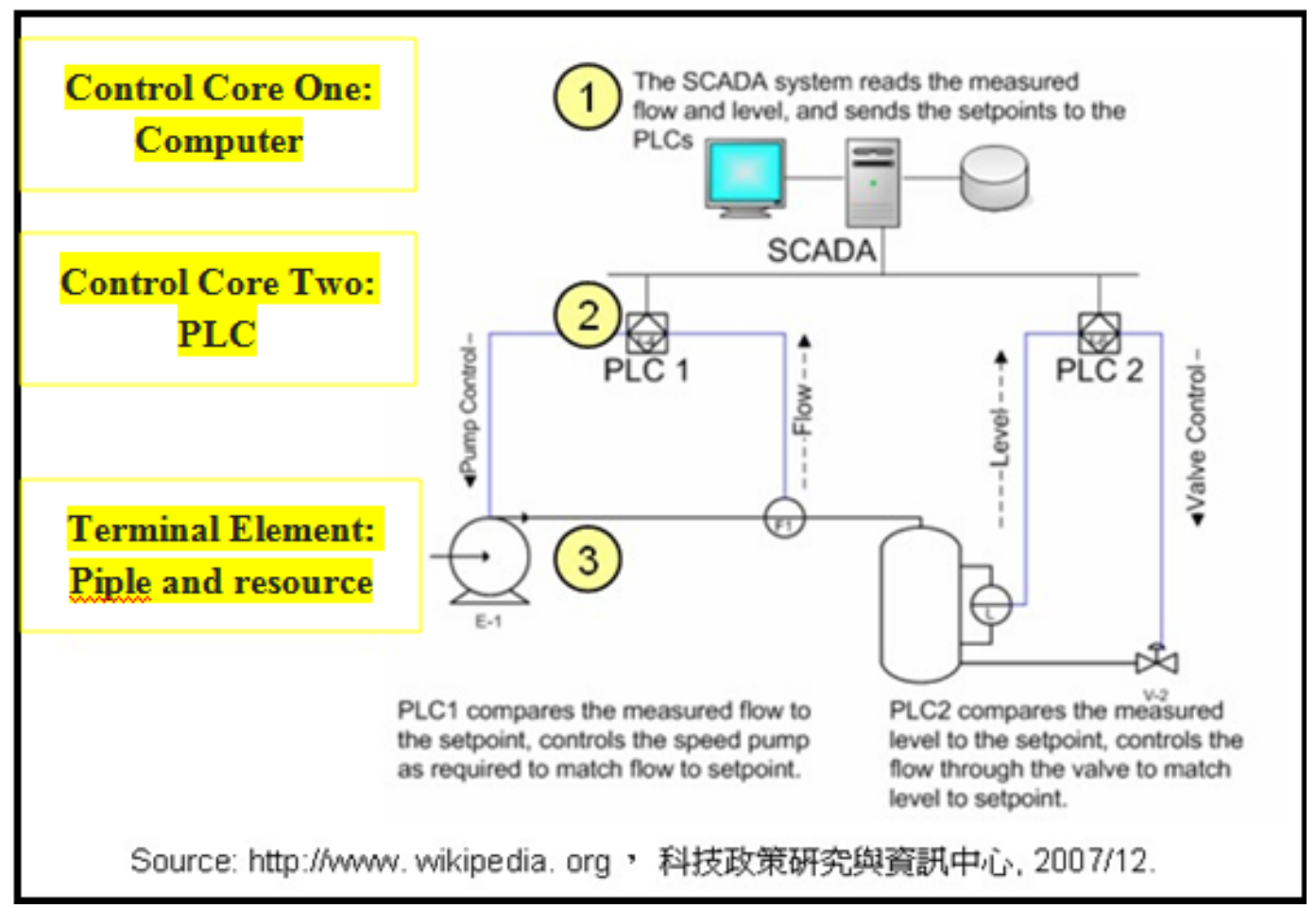

Fig. 5 SCADA schematic diagram.

IP Address (internet protocol address), Host Name, Domain Name (edu, net, com, gov, org), etc., we just illustrate one of the most important typical network mechanism: Cloud Computing as follows.

The cloud computing industry is recognized as being divided into three levels: cloud software, cloud platforms, and cloud infrastructure.

The upper level: SaaS (software as a service), breaking the monopoly of the past, everyone can freely utilize their ideas and provide a wide range of software services. Participants: Software developers around the world.

Middle level: PaaS (platform as a service), set up a program development platform and operating system platform. Developers can write programs and provide software services through the Internet. Consumers can also execute programs on them. Participants: Google, Microsoft, Apple, Yahoo.

The lower level: IaaS (infrastructure as a service) integrates basic equipment such as storage space, operating systems, database, etc., and is divided into different rooms like offices to be leased by enterprises.
Participants: Inventec, IBM, Dell, Sun, HP, Amazon.

In the supplier chain system, no matter the companies are Brand owners, CMMS, EMS, ODM or OEM, for the all participants in the SIPOC process are required to satisfy customer's basic requirements: quality, cost, delivery. However, the customer's product add value to all the participants in supplier chain when at the moment that consumers paid money to buy the product and service. Therefore, all the people doing business in supplier chain can collaborate efficiently and share business information accurately, is the way to assure quality, lower cost, on time delivery for the customer. Recently, most companies in the supplier chain of high technology have been required to meet the requirements from many kinds of quality system standard, like as ISO 9001, ISO TS 16949, etc., and got some positive performance. But, there is a kind of supplier chain management system under cloud computing mechanism can offer quality, stock, production information from different companies in the supplier chain, let all the people doing business in supplier 
chain can collaborate efficiently and share business information accurately. We try to depict the system planning of SCM under cloud computing mechanism.

The cloud SCM what we conceive of architecture planning, each user's account database is only related to the upper level customer or the lower level supplier, just like the Markov Chain. The Markov chain is a discrete-time stochastic process with nature in mathematics, in this kind of process, given the current knowledge or information, only the current state is related to predict the future. The Markov chain is a sequence of random variables $X_{0}, X_{1}, X_{2}, \ldots, X_{n}$, the set of all their possible values, is called the "state space" and the $X_{n}$ value is the state at time $n$. If the conditional probability distribution of $X_{n+1}$ to the past state is only a function of $X_{n}$, then

$$
P\left[X_{n+1}=x \mid X_{n}, X_{n-1}, \ldots, X_{0}\right]=P\left[X_{n+1}=x \mid X_{n}\right]
$$

The Cloud SCM provides all users' account with the same software and database of the same structure; and each user independently accesses its own database, so the contents and storage location of the database are different, but the database between users can be interchanged. Each user can only authorize their upper-level customers or lower-level suppliers to maintain the authorized database. Therefore, each user forms a small-scale supply chain system. The suppliers under the customer-ordered project are connected in series to form a large-scale cloud SCM, as shown in Fig. 6.

The above cloud SCM operating management system is described as follows: Regardless of whether the users in the cloud are in the supply chain or the demand chain, the user connects to the supply side, which is the customer's supply chain system to the suppliers (downward supply chain); the user connects to the demand side, which is the supplier's supply chain system to the customers (upward supply chain). The downward supply chain, orders are placed to the relevant suppliers, and the suppliers plus the product models to create a project, and the supplier is requested to provide the production inventory and quality information of the order to ensure timely delivery. Similarly, the upward supply chain, if the user

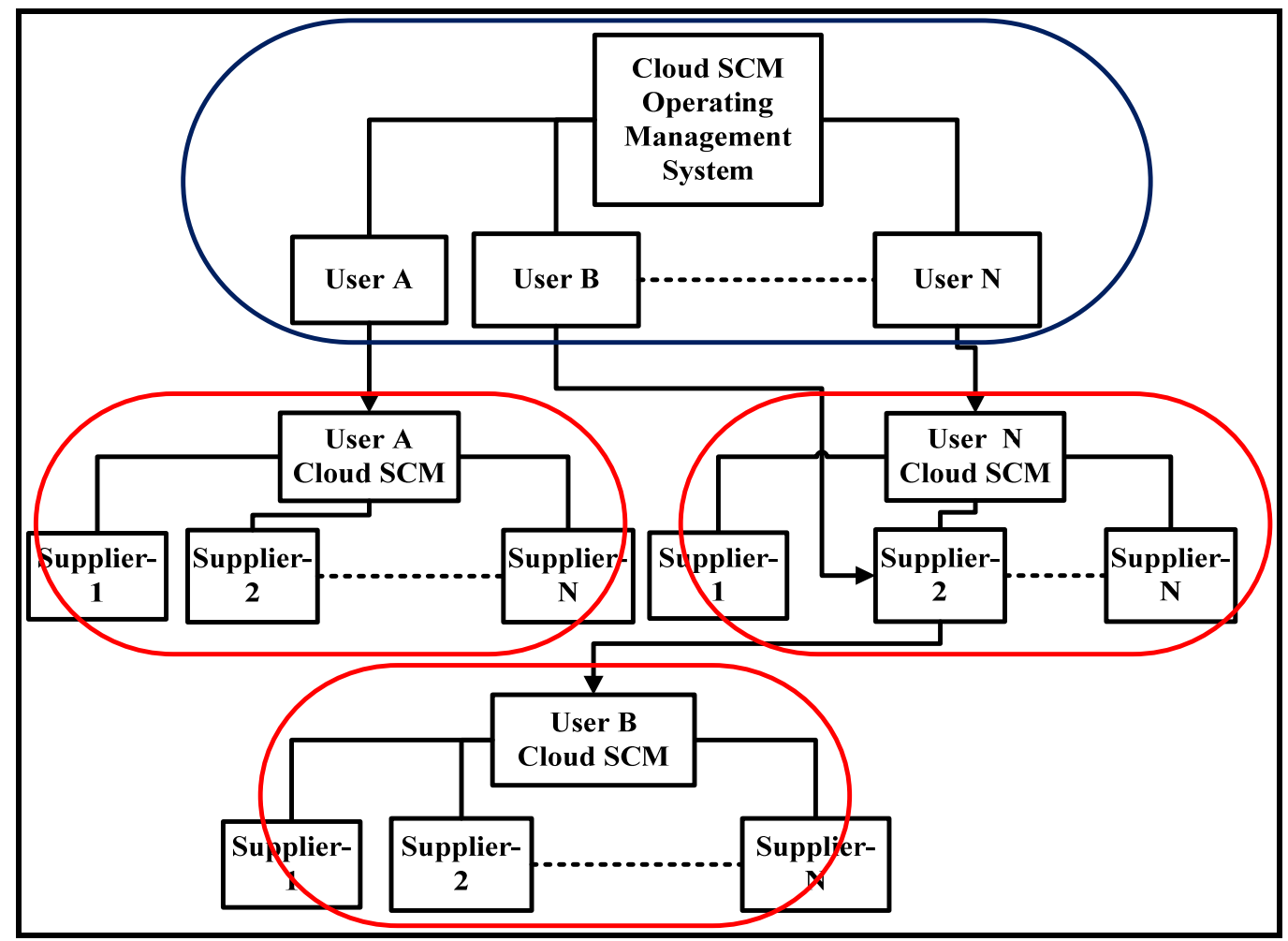

Fig. 6 Cloud SCM. 
is in the supply chain, accepts orders from different customers, establishes a project with customers plus product models, and requests customers to provide sales inventory and quality information in order to accurately predict the future demand of the customers. These two kinds of business models are popular in different industries nowadays, and the cloud SCM system can be a solution to enhance the business operating effectiveness and efficiency.

\section{Application Layer}

In application layer: DBMS, MES, ERP, PLM, CRM, SCM are the application software systems popularly implement from supplier chain: purchasing, production controlling, incoming, production and shipping to demand chain: ordering, logistics delivery, retail, and maintain service, it can integrate the all processes to be a value chain through the computation, communication, controlling, collaboration and real time response of the functions which the software systems provided. We just illustrate the basic tool: Database Management System as follows.

The data stored in the database is structured in an orderly manner, that is, a combination from small to large. The smallest unit is the bit, and the largest unit is the database. For the convenience of data storage and processing, we can effectively manage data, and divide the data into several levels according to the size and mutual relationship of the units. The explanation is as follows: Bit $\rightarrow$ Byte $\rightarrow$ Field $\rightarrow$ Record $\rightarrow$ File/Table $\rightarrow$ Database. As shown in Fig. 7: An example of SPC database, variable database and attribute database, Fig. 8: An example of variable SPC analysis and Fig. 9: An example of attribute SPC analysis.

Database management is the software used to manage the database as an interface between the user and the database. Fig. 10 shows an example of a QKM

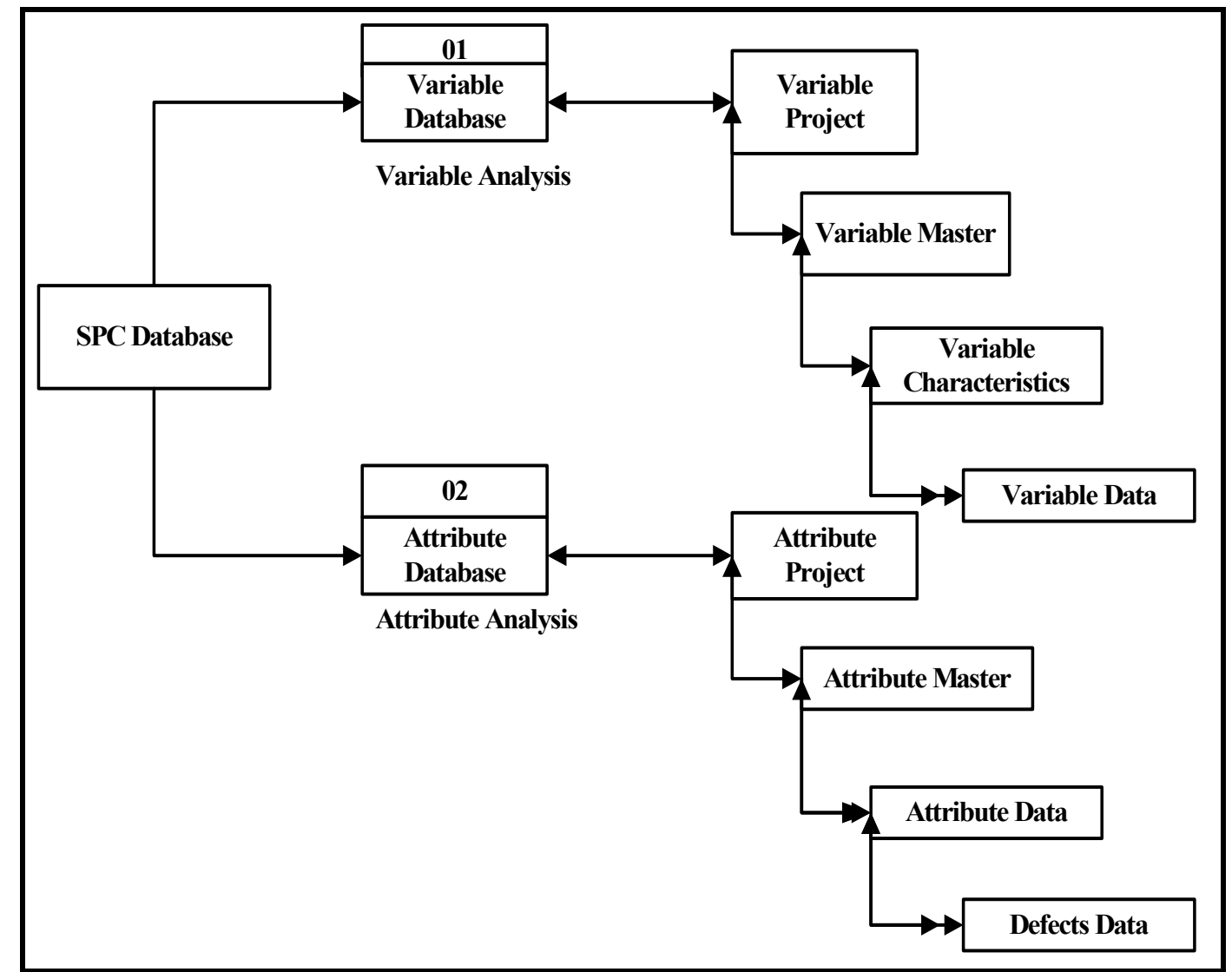

Fig. 7 An example of SPC database. 


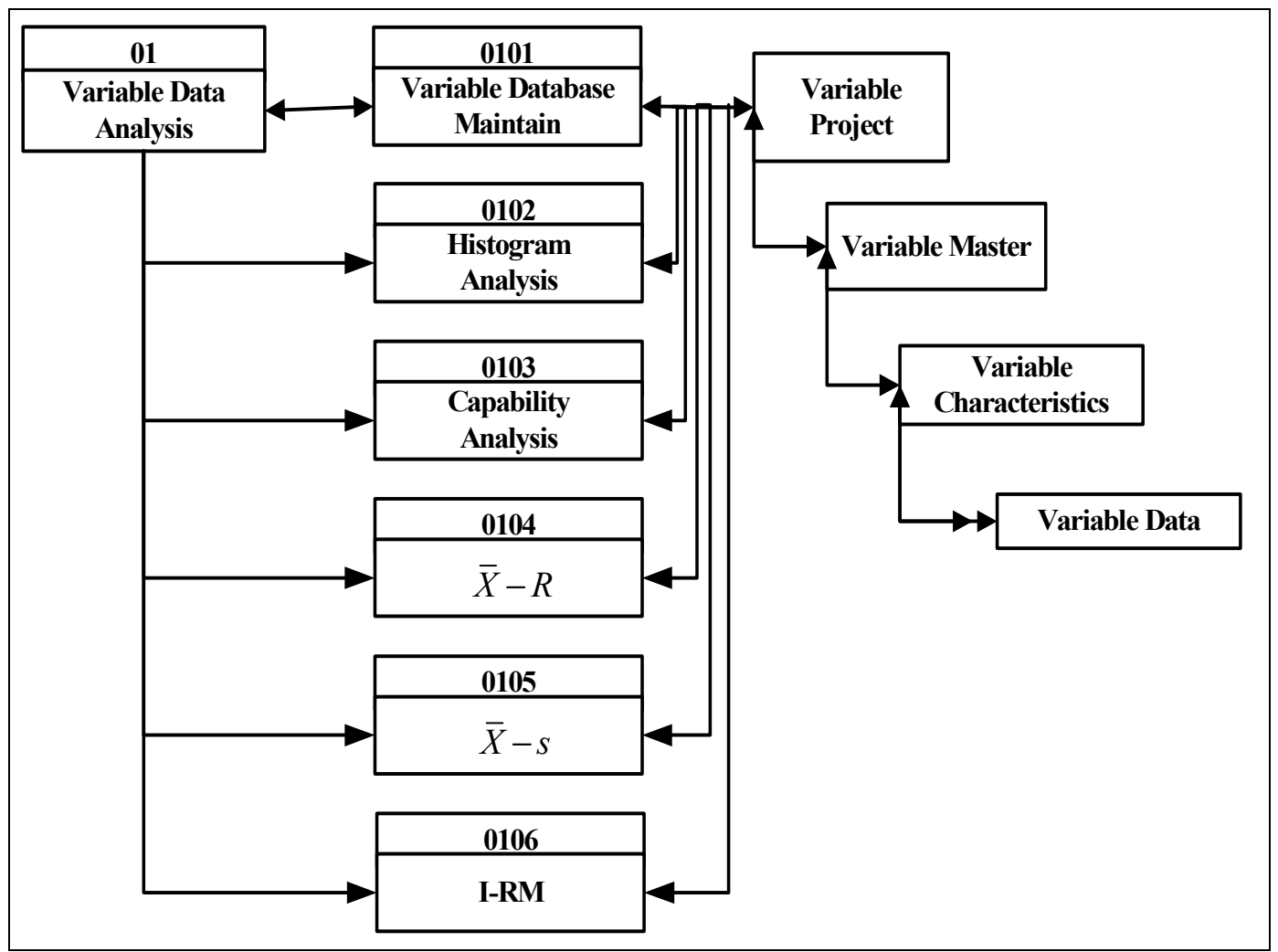

Fig. 8 An example of variable SPC analysis.

- Variable Master

\begin{tabular}{llll}
\hline Field & Field Name & Type & Description \\
\hline 1 & DATANAME & Character & Master File Name \\
2 & KEY1NAME & Character & Index 1 Name \\
3 & KEY2NAME & Character & Index 2 Name \\
4 & KEY3NAME & Character & Index 3 Name \\
5 & MEMO & Character & MEMO \\
\hline$\bullet$ Variable Characteristics & & \\
\hline Field & Field Name & Type & Description \\
\hline 1 & DATANAME & Character & Master File Name \\
2 & SEQUENCE & Character & SEQUENCE No \\
3 & CHARACTER & Character & CHARACTER Name \\
4 & UNIT & Character & UNIT \\
5 & USPEC (USL) & Floating & USPEC (USL) \\
6 & NOMINAL (TARGET) & Floating & NOMINAL (TARGET) \\
7 & LSPEC (LSL) & Floating & LSPEC (LSL) \\
8 & SAMSIZE & Integer & SAMSIZE \\
9 & INT & Integer & INT \\
10 & DEC & Integer & DEC \\
11 & MEAN & Floating & MEAN \\
12 & SIGMA & Floating & SIGMA \\
13 & MEMO & Character & MEMO \\
\hline
\end{tabular}


- Variable Data

\begin{tabular}{llll}
\hline Field & Field Name & Type & Description \\
\hline 1 & DATE & Data & DATE \\
2 & TIME & Time & TIME \\
3 & KEY 1 & Character & Index 1 Name \\
4 & KEY 2 & Character & Index 2 Name \\
5 & KEY 3 & Character & Index 3 Name \\
6 & $\mathrm{X}_{1}$ & Floating & Data 1 \\
7 & $\mathrm{X}_{2}$ & Floating & Data 2 \\
. & $\cdot$ & . & . \\
8 & $\mathrm{X}_{n}$ & Floating & Data $n$ \\
9 & MEMO & Character & MEMO \\
\hline
\end{tabular}

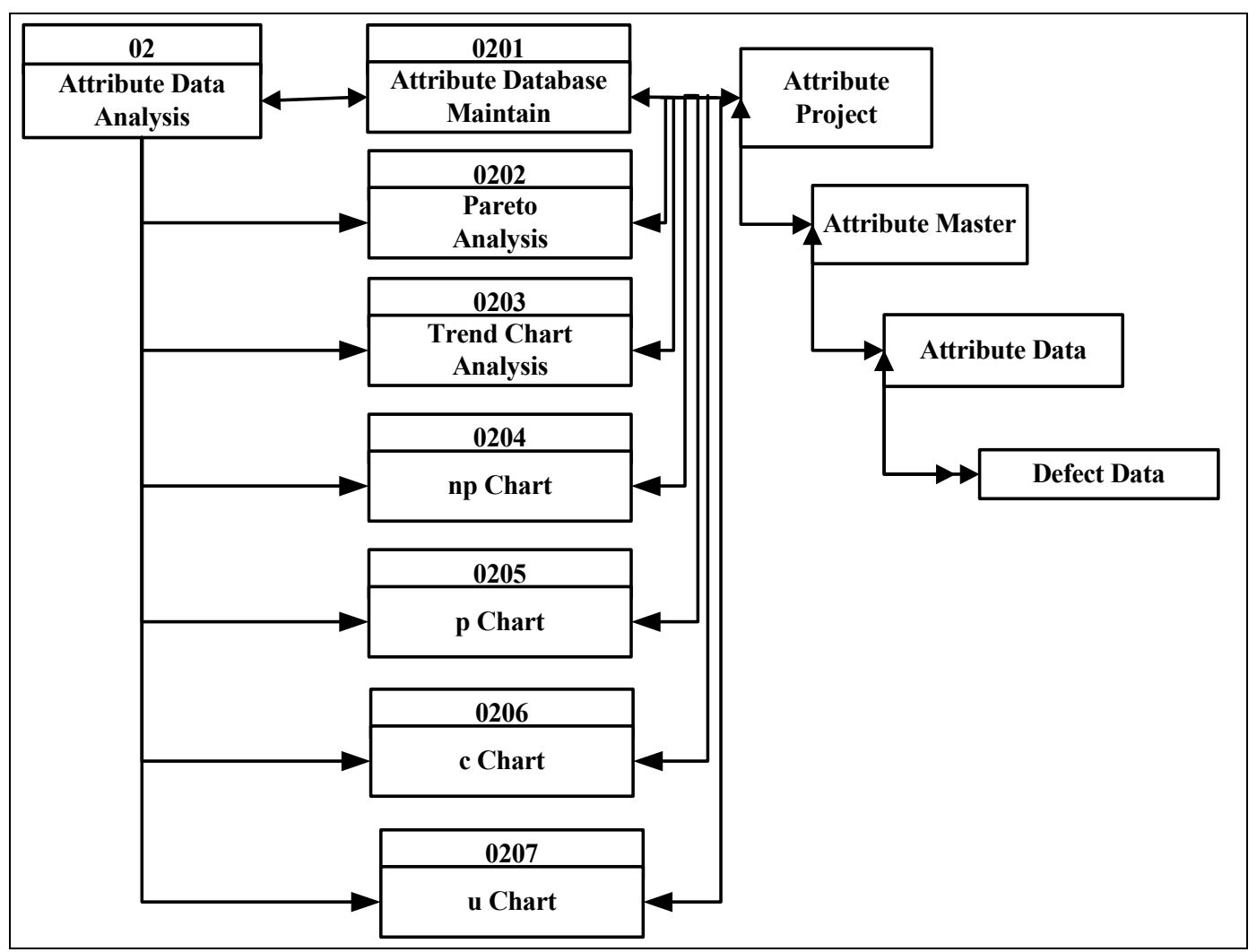

Fig. 9 An example of attribute SPC analysis.

- Attribute Master

\begin{tabular}{llll}
\hline Field & Field Name & Type & Description \\
\hline 1 & DATANAME & Character & Master File Name \\
2 & KEY1NAME & Character & Index 1 Name \\
3 & KEY2NAME & Character & Index 2 Name \\
4 & KEY3NAME & Character & Index 3 Name \\
5 & CHART & Character & Statistics \\
6 & INT & Integer & INT \\
7 & DEC & Integer & DEC \\
8 & FIGTYPE & Character & FIGTYPE (\%, \#.\#, \#\#) \\
9 & DEFQTY & Floating & Defectives/Defects \\
10 & MEMO & Character & MEMO \\
\hline
\end{tabular}


- Attribute Data

\begin{tabular}{llll}
\hline Field & Field Name & Type & Description \\
\hline 1 & DATE & Date & Date \\
2 & KEY1 & Character & Index 1 Name \\
3 & KEY2 & Character & Index 2 Name \\
4 & KEY3 & Character & Index 3 Name \\
5 & PRODQTY & Floating & Lot Size \\
6 & CHKPTS & Floating & Opportunities \\
7 & INSPQTY & Floating & Inspection QTY \\
8 & DEFQTY & Floating & Defectives/Defects QTY \\
9 & MEMO & Character & MEMO \\
\hline$\bullet$ & Pareto Data & & \\
\hline Field & Field Name & Type & Description \\
\hline 1 & DATE & Date & Date \\
2 & KEY1 & Character & Index 1 Name \\
3 & KEY2 & Character & Index 2 Name \\
4 & KEY3 & Character & Index 3 Name \\
5 & DEFCODE & Character & Defectives/Defects Code \\
6 & DEFNAME & Character & Defectives/Defects Name \\
7 & DEFQTY & Floating & Defectives/Defects QTY \\
8 & DEFCAUSE & Character & Defects Cause \\
\hline
\end{tabular}

architecture diagram. Users can use the database management system to add, update, delete, inquire, and print data.

\section{Value Integration and Continuous Improvement Layer}

The development of future quality professional fields will still develop a wide range of fields, based on the material and spiritual needs of human beings. The platform provided by Internet-based information technology, system integration theory will be an important knowledge and technology, such as human-machine integration, machines integration, information systems integration, supply chain integration, network entity integration, value integration, knowledge integration, ideological integration, and wisdom integration.
In terms of micro-industrial development, Industry 4.0 will create many kinds of innovative business model via customized design and marketing, from supplier chain: purchasing, production controlling, incoming, production and shipping to demand chain: ordering, logistics delivery, retail, and maintain service, it can integrate the all processes to be a value chain through computation, communication, controlling, collaboration and real time response.

System integration engineering focuses on system-value-added integration between software and hardware. The process of value-added integration is nothing more than system planning, system analysis, and system design, project outsourcing and programming, unit testing, system and integration testing, user acceptance testing, and system acceptance. Fig. 11 shows the V shape model. 


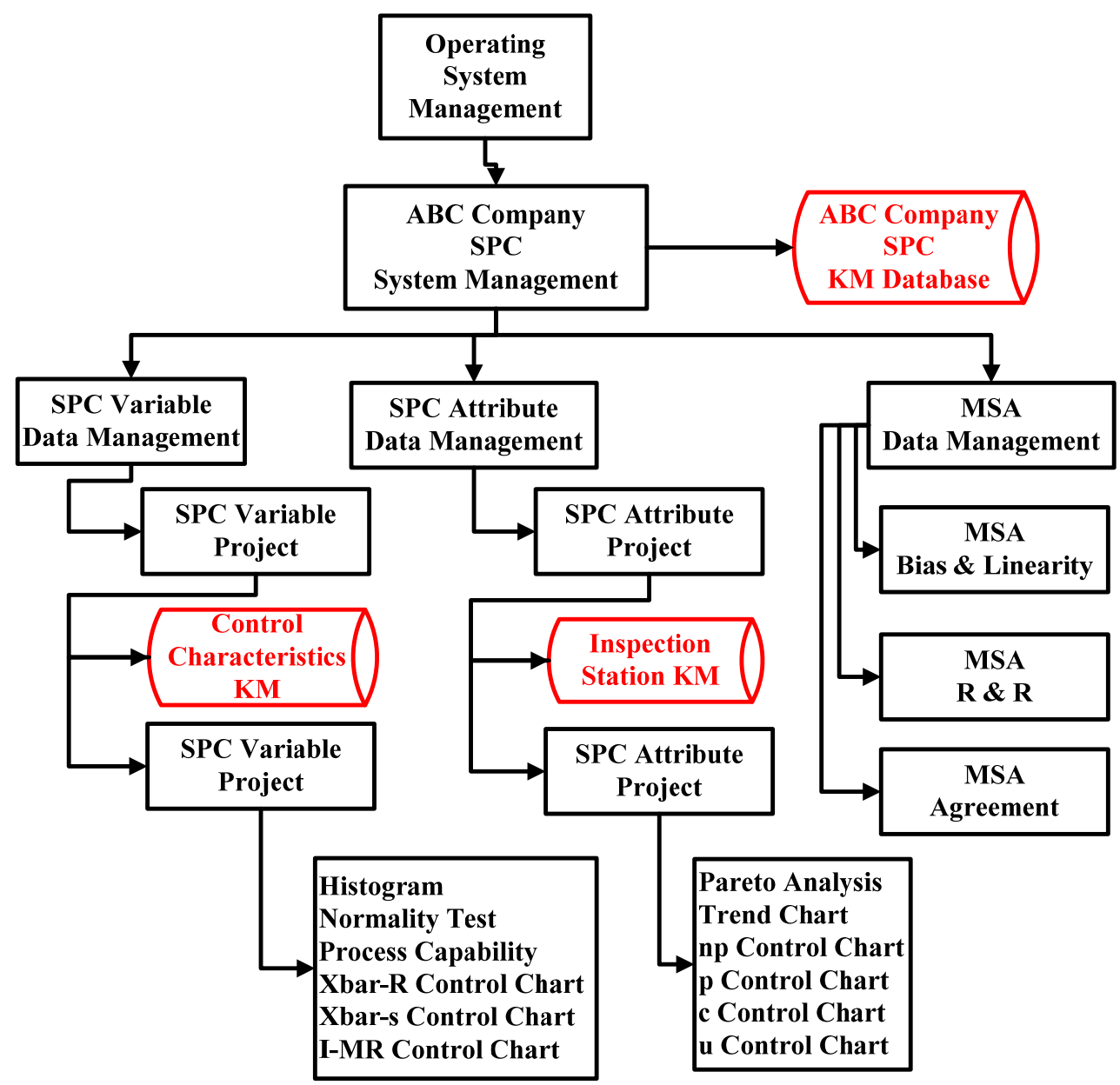

Fig. 10 QKM architecture diagram.

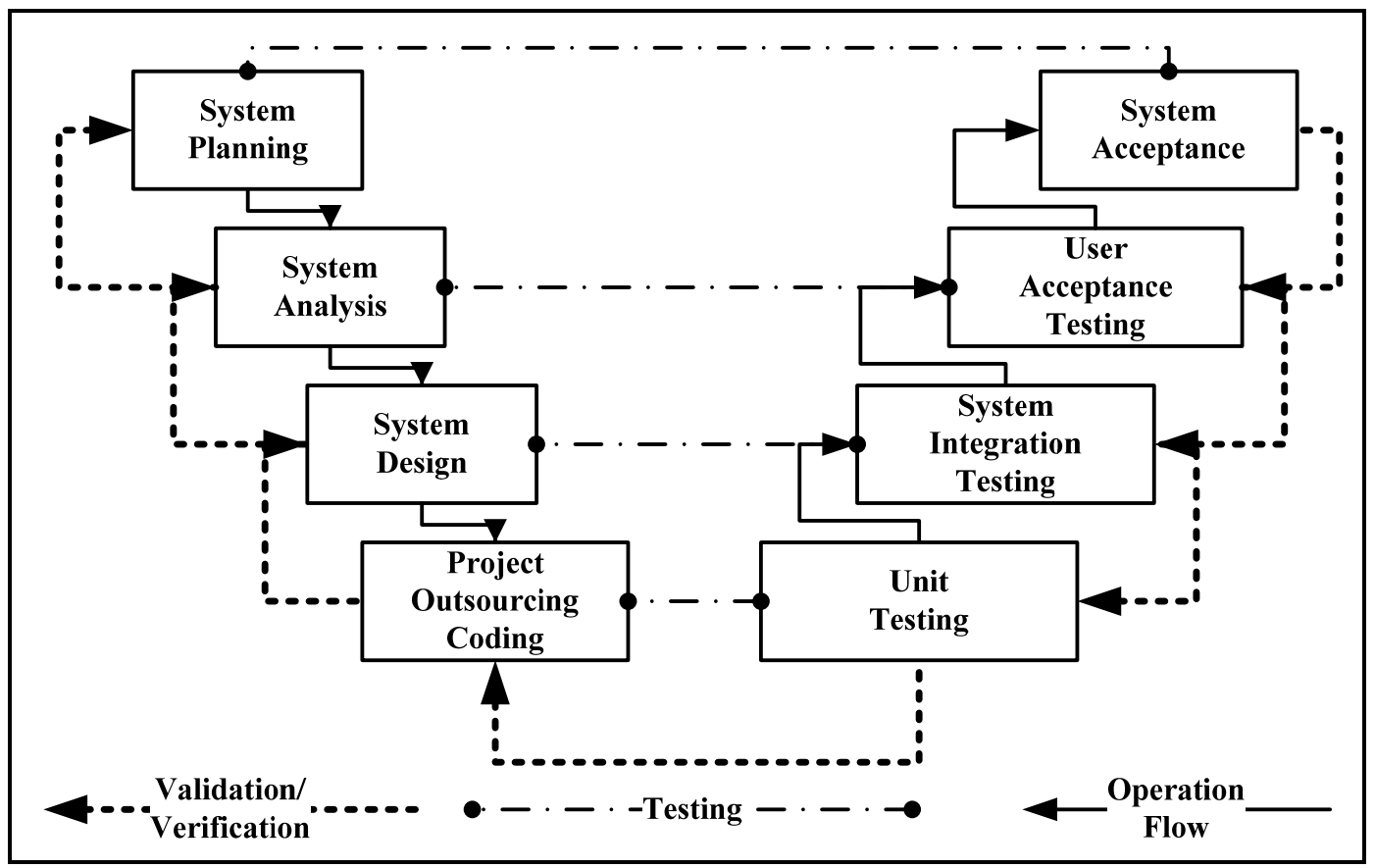

Fig. 11 The V shape model. 


\section{Conclusion}

The quality requirements of all processes of the value chain of Industry 4.0 would be much more transparent. As the demand chain, product and service will be required more accurate, speedy, reliable, safety, ecological, and environmental. As the supplier chain, the product and service will be required more easily to design, manufacture, change, transport, maintain, recycle and trace. Therefore, quality practitioners should pay more attention to the requirements of all processes of the value chain in the future.

\section{References}

[1] Kuan, S. P. 1996. SPC Statistical Process Control-Computerization, Automation, Real-time and Integration. Published by CSQ in Taiwan.

[2] Science \& Technology Policy Research and Information Center (財團法人國家實驗研究院科技政策研究與資訊 中心科技產業資訊室). http://cdnet.stpi.narl.org.tw/tech room/pclass/2008/pclass_08_A002.htm. 